\title{
GERMINAÇÃO E CRESCIMENTO INICIAL DE PLÂNTULAS DE Euphorbia beterophylla L. E Glycine max L. Merril NA PRESENÇA DE EXTRATOS FOLIARES DE Salvia officinalis $\mathrm{L}$.
}

\author{
Angélica Luana Kehl da Silva* \\ Karla Gabriela da Silva* \\ Roberta Paulert" \\ Patrícia da Costa Zonetti** \\ Leandro Paiola Albrecht**
}

RESUMO: As plantas daninhas têm apresentado múltipla resistência devido ao uso intensivo de herbicidas. Uma alternativa adicional no manejo destas plantas seria a exploração da potencialidade alelopática de plantas para futura bioprospecção. Este trabalho teve o objetivo de avaliar a bioatividade do extrato de sálvia (Salvia officinalis L.) sobre a germinação e crescimento inicial de plântulas de amendoim-bravo (Euphorbia beterophylla L.) e soja (Glycine max L. Merril). Os extratos foram obtidos por trituração de folhas frescas e secas, na proporção de $1 \mathrm{~g}$ para $5 \mathrm{~mL}$ de água destilada. Os tratamentos consistiram do extrato bruto e diluído a 50\%. No grupo controle foi utilizada apenas água destilada. As sementes e plântulas foram expostas aos extratos em condições controladas, em estufa do tipo B.O.D. a $25^{\circ} \mathrm{C}$. Ao final de sete dias foram avaliadas as variáveis: porcentagem de germinação $(\% \mathrm{G})$, índice de velocidade de germinação (IVG), crescimento da raiz principal e da parte aérea além das biomassas frescas e secas destes órgãos. Foi observado que os extratos não afetaram a $\% \mathrm{G}$ de ambas as espécies, no entanto, promoveram atrasos no processo. $\mathrm{O}$ crescimento da raiz de amendoim-bravo foi afetado pelos dois tipos de extrato bruto e diluído, e o crescimento da parte aérea foi reduzido com extrato da folha fresca. O crescimento das plântulas de soja foi estimulado na presença dos extratos. Os resultados indicam possível ação alelopática inibitória de folhas de sálvia sobre o crescimento de plântulas de amendoim-bravo, e ação estimulatória sobre o crescimento das plântulas de soja.

PALAVRAS-CHAVE: Alelopatia; Extrato Vegetal; Planta Daninha.

\footnotetext{
"Curso de Tecnologia em Biotecnologia da Universidade Federal do Paraná (UFPR), Setor Palotina (PR), Brasil.

* Curso de Agronomia Universidade Federal do Paraná (UFPR), Setor Palotina (PR), Brasil.

E-mail: patriciazonetti@ufpr.br
} 


\title{
GERMINATION AND INITIAL GROWTH OF Euphorbia beterophylla L. AND Glycine max L. Merril SEEDLINGS WITH LEAF EXTRACTS OF Salvia officinalis $\mathrm{L}$.
}

\begin{abstract}
Weeds have shown great resistance against intensive use of herbicides. An additional management alternative of the plants would be the use of plants allelopathic potentiality for future bioprospection. Current paper assesses the bioactivity of salvia extract (Salvia officinalis L.) on the germination and initial growth of the wild poinsettia (Eupborbia beterophylla L.) and soybean (Glycine max L. Merril). Extract were retrieved from the grinding of fresh and dry leaves at the proportion of $1 \mathrm{~g}$ to $5 \mathrm{~mL}$ of distilled water. Treatments comprised crude and diluted extract at 50\%. Control group comprised only distilled water. Seeds and plants were exposed to the extracts under controlled conditions in a BOD buffer at $25^{\circ} \mathrm{C}$. The variables germination percentage $(\% \mathrm{G})$, germination speed index (GSI), growth of main roots and the aerial part, and fresh and dry biomass of the organs were evaluated after seven days. Extracts failed to affect \% $\mathrm{G}$ of the two species but delayed the process. Growth of the wild poinsettia roots was affected by the two types of crude and diluted extract and the growth of the aerial section was reduced by the fresh leaf extract. The growth of soybean seedlings was stimulated by the extracts. Results show possible allelopathic inhibitory activity of salvia leaves on the growth of wild poinsettia seedlings and enhancement on the growth of soybean seedlings
\end{abstract}

KEY WORDS: Allelopathy; Vegetal Extract; Weeds.

\section{INTRODUÇÃO}

As substâncias alelopáticas são encontradas em concentrações variadas em diferentes partes da planta. Ao serem liberadas no ambiente podem causar inibição ou estimular a germinação, crescimento e/ou desenvolvimento de plantas já estabelecidas e, ainda, o desenvolvimento de microrganismos (CARVALHO, 1993; KATONOGUSHI; INO, 2001).

O conceito de alelopatia descreve a influência de um indivíduo sobre o outro em um ecossistema por meio de biomoléculas, aleloquímicos, produzidas pelas plantas, seja prejudicando ou favorecendo a planta alvo (RIZVI et al., 1999). Nos últimos anos estudos sobre alelopatia têm enfocado a sua aplicação na agricultura, tornando-se uma importante ferramenta para prospecção de plantas que 
apresentam compostos bioativos (OLIVEROS-BASTIDAS, 2008) a partir dos quais podem ser produzidos herbicidas naturais, mais específicos e menos prejudiciais ao ambiente (MACIAS et al., 1998). Substâncias produzidas pelas plantas ou mesmo por microrganismos podem oferecer novas e excelentes oportunidades para diversificar o controle de plantas daninhas nas culturas, reduzindo ou eliminando a contaminação do ambiente, preservando os recursos naturais e garantindo o oferecimento de produtos agrícolas com alta qualidade, desprovidos de resíduos contaminantes (WANDSCHEER; PASTORINI, 2008; SOUZA FILHO et al., 2009).

A sálvia (Salvia officinalis L.) é uma espécie da família Lamiaceae que se destaca pela sua ação medicinal na medicina popular (LORENZI; MATOS, 2002) e também por seus efeitos alelopáticos. Esta planta libera substâncias químicas que podem inibir o crescimento de outras plantas; apresenta como princípio ativo óleos essenciais como cineol, cânfora, borneol, tuiona, ácido rosmarínico, flavonóides, taninos, substância estrogênica e saponinas (SILVA et al., 1995; MARTINS et al., 2002).

Euphorbia beterophylla L. é uma planta daninha conhecida como amendoim-bravo ou leiteira infestante das lavouras do Paraná, acometendo principalmente a cultura da soja. Pela dificuldade de seu controle químico devido à resistência adquirida, alternativas vêm sendo estudadas, dentre estas ensaio de alelopatia. Estes estudos relacionados à ação alelopática de plantas são úteis na busca de novas moléculas com ação herbicida ou reguladora de crescimento. Dessa forma uma possível indicação é o uso de extratos de plantas medicinais, que podem inibir o crescimento da planta daninha. Gusman et al. (1990) demonstraram que o citronelol, constituinte do óleo essencial de espécies cítricas, inibiu a germinação de sementes e o crescimento inicial de leiteiro (Euphorbia beterophylla L.).

O objetivo do presente trabalho foi avaliar o efeito de extratos de folhas frescas e secas de sálvia sobre a germinação e crescimento inicial da soja e amendoim-bravo.

\section{MATERIAL E MÉTODOS}

Foram preparados extratos aquosos da folha fresca e seca de sálvia na concentração de $1 \mathrm{~g}$ de massa vegetal para $5 \mathrm{~mL}$ de água destilada. Para preparação dos 
extratos aquosos das folhas frescas foram utilizadas folhas de sálvia lavadas e trituradas em liquidificador. Para o preparo das folhas secas, as mesmas foram levadas à estufa por 48 horas a $40^{\circ} \mathrm{C}$ antes da trituração e homogeneização em água. Após a trituração, os extratos foram filtrados em gaze e algodão.

Os tratamentos consistiram de: T1 - extrato bruto (100\%) de folhas frescas; T2 - extrato diluído $50 \%$ de folhas frescas; T3 - extrato bruto (100\%) de folhas secas; T4 - extrato diluído $50 \%$ de folhas secas; T5 - controle. No grupo controle foi utilizada apenas água destilada. Todos os tratamentos foram repetidos quatro vezes.

No bioteste de germinação cinquenta sementes de soja cultivar BMX Potência RR e de leiteira (adquiridas na empresa Agrocosmos) foram dispostas em caixas gerbox forradas com papel germitest previamente umedecido com $8 \mathrm{~mL}$ de extrato por placa no primeiro dia, nos outros dias as placas foram umedecidas com $4 \mathrm{~mL}$. As contagens de germinação foram realizadas todos os dias. No final do período de avaliação foram obtidos a porcentagem de germinação $(\% \mathrm{G})$ e o índice de velocidade de germinação (IVG). O cálculo de IVG foi obtido pelo somatório do número de sementes germinadas a cada dia, dividido pelo número de dias decorridos entre a semeadura e a germinação.

No bioteste de crescimento vinte plântulas crescidas por sete dias em papel com água destilada foram dispostas em rolos de papel germitest umedecidas com os diferentes tratamentos. Após sete dias, foram medidas a raiz primária e a parte aérea das plântulas, com auxílio de régua. Foram então pesadas a parte aérea e a raiz. Em seguida, foram colocadas em estufa a $60^{\circ} \mathrm{C}$ por 24 horas pesando-se após para obtenção da biomassa seca da parte aérea e da raiz. O crescimento foi obtido pela diferença entre o comprimento final e inicial e pelas medidas de biomassa fresca e seca.

Todos os ensaios permaneceram em câmara de germinação tipo B.O.D com temperatura de $25^{\circ} \mathrm{C}$ e fotoperíodo de 12 horas.

O delineamento experimental foi inteiramente casualizado. Os resultados foram submetidos a análise de variância, e quando significativo ao teste de Tukey a $5 \%$ de significância. 


\section{RESULTADOS E DISCUSSÃO}

Após a análise dos dados observou-se que a \%G de ambas as espécies não foi afetada pelos diferentes extratos. No entanto, o extrato bruto de folhas secas promoveu atraso na germinação do amendoim-bravo (Figura 1A) e o extrato de folhas frescas sobre as sementes de soja (Figura 1B).

O comprimento da raiz assim como a biomassa fresca de plântulas de soja foi afetado pelo extrato aquoso das folhas secas, revelando um estímulo no crescimento do órgão vegetal na presença do extrato (Figuras 2A e B). Em relação à planta daninha, os extratos brutos (folha seca e fresca) promoveram redução no comprimento da raiz das plântulas (Figura 3). O extrato de folhas secas a 50\% reduziu biomassa seca das raízes (Figura 4).

Em relação ao crescimento da parte aérea, observou-se que o comprimento caulinar das plântulas de soja foi afetado pelo extrato das folhas frescas, havendo um estímulo no alongamento (Figura 7). O comprimento da parte aérea, assim como a biomassa seca da planta daninha amendoim-bravo, foi reduzido na presença do extrato obtido com folhas frescas (Figuras 8 e 9). A biomassa fresca foi reduzida na presença do extrato de folhas secas (Figura 10).

De forma geral, nas plântulas de soja, verificou-se que os extratos estimularam o crescimento das mesmas enquanto que no amendoim-bravo observou-se redução nos parâmetros de crescimento avaliados.
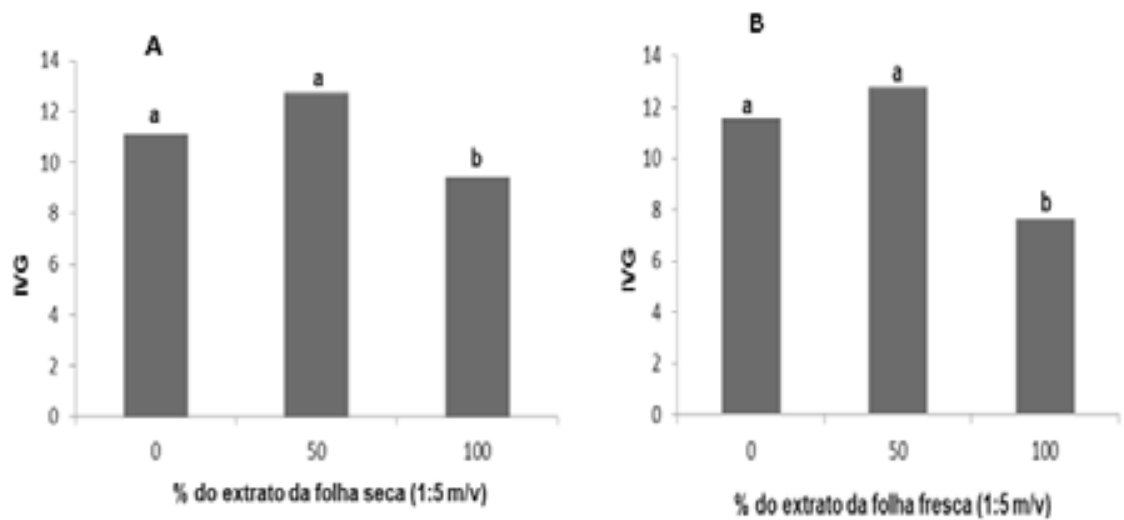

Figura 1. A: Índice de Velocidade de Germinação de amendoim-bravo no extrato aquoso da folha seca de sálvia. B: Índice de Velocidade de Germinação de sementes de soja com extrato aquoso da folha fresca de sálvia. Letras iguais representam tratamentos iguais pelo teste de Tukey a 5\%. 
A

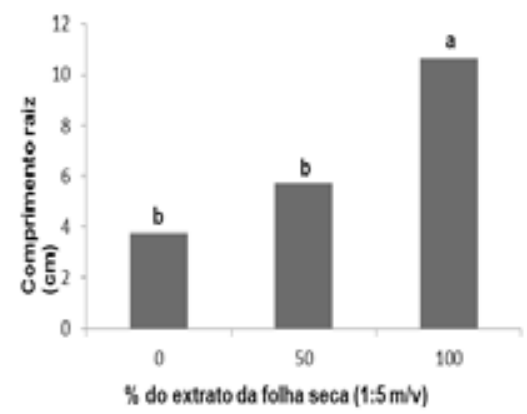

B

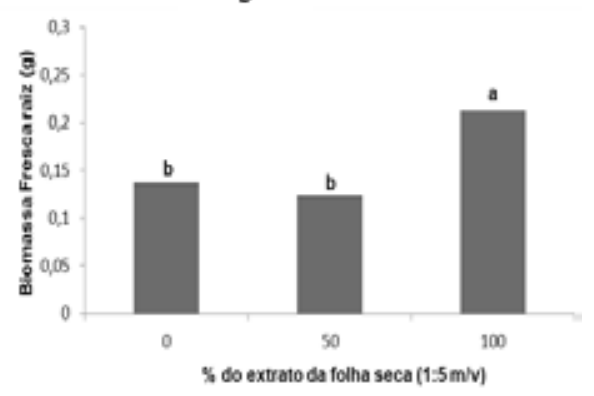

Figura 2 A. Comprimento da raiz de soja no extrato aquoso da folha seca de sálvia. B. Biomassa fresca da raiz de soja no extrato aquoso de folha seca de sálvia. Letras iguais representam tratamentos iguais pelo teste de Tukey a 5\%.

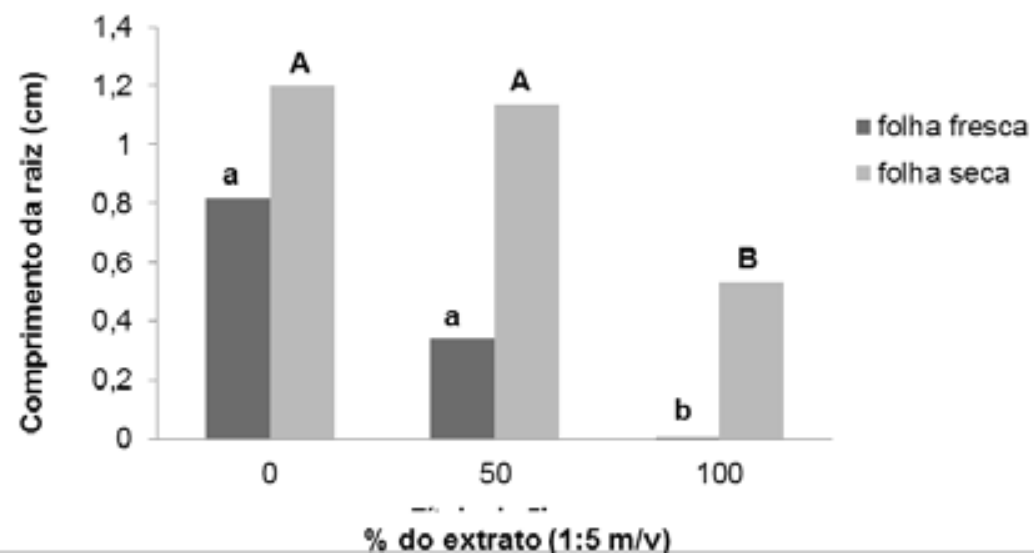

Figura 3. Comprimento da raiz de amendoim-bravo em ambos os extratos aquosos. Letras minúsculas comparam dentro do extrato da folha fresca e letras maiúsculas dentro de extrato da folha seca. Letras iguais representam tratamentos iguais pelo teste de Tukey a 5\%. 


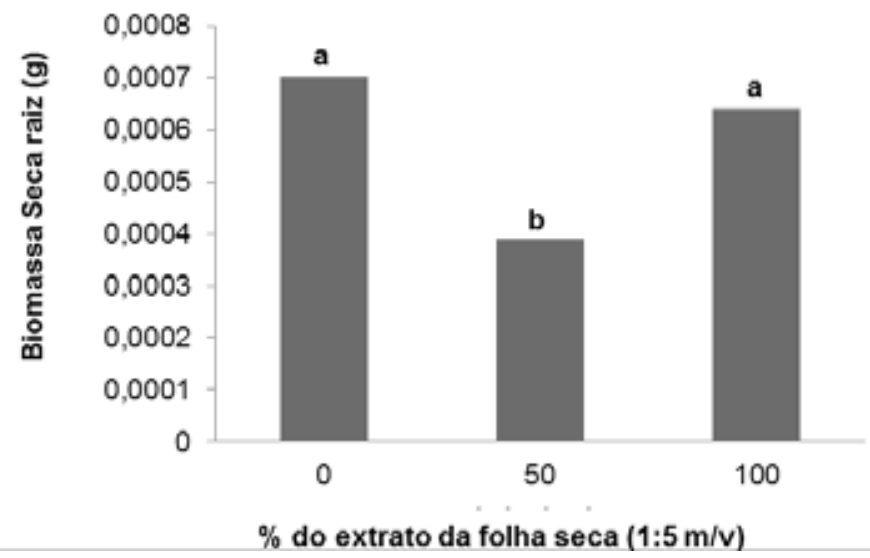

Figura 4. Biomassa seca da raiz de amendoim-bravo no extrato aquoso de folha seca de sálvia. Letras iguais representam tratamentos iguais pelo teste de Tukey a 5\%.

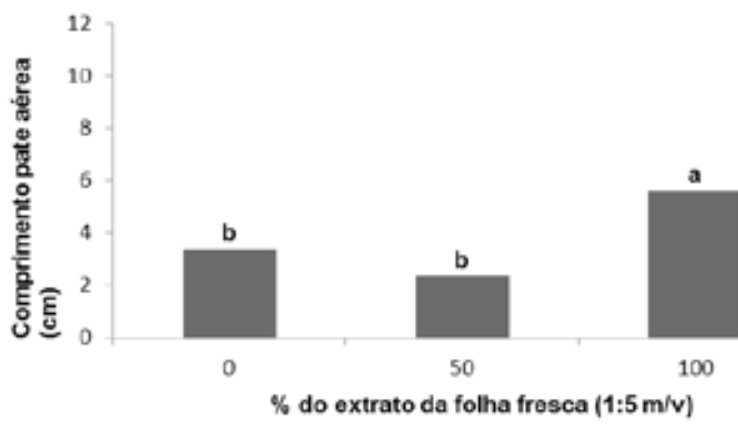

Figura 5. Comprimento da parte aérea de soja no extrato aquoso da folha fresca de sálvia. Letras iguais representam tratamentos iguais pelo teste de Tukey a 5\%. 


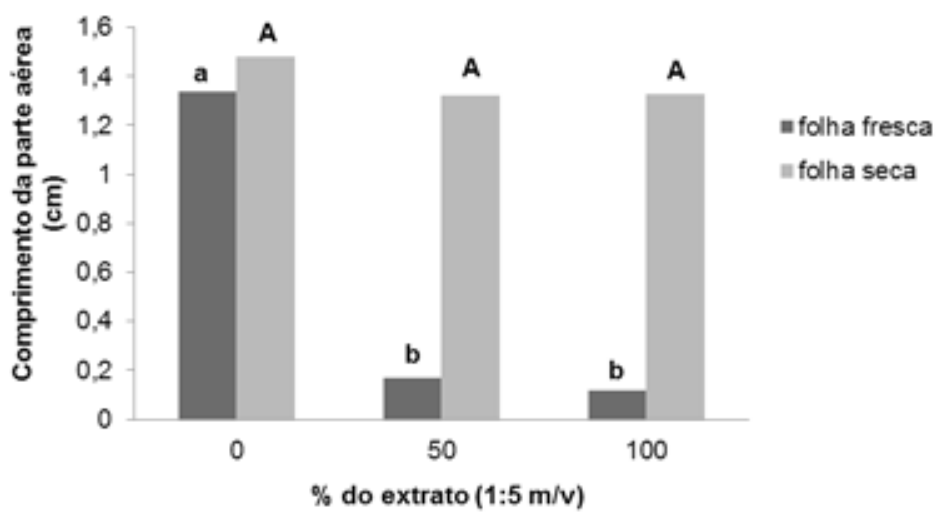

Figura 6. Comprimento da parte aérea de amendoim-bravo em ambos os extratos aquosos. Letras minúsculas comparam dentro do extrato da folha fresca e letras maiúsculas dentro de extrato da folha seca. Letras iguais representam tratamentos iguais pelo teste de Tukey a 5\%.
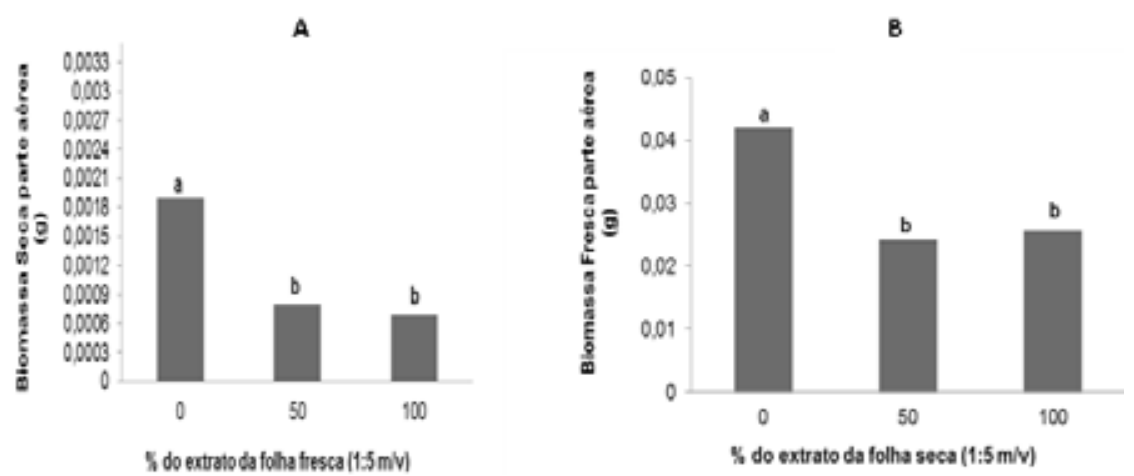

Figura 7 A. Biomassa seca da parte aérea de amendoim-bravo no extrato aquoso da folha fresca de sálvia. B. Biomassa fresca da parte aérea de amendoim-bravo no extrato aquoso da folha seca de sálvia. Letras iguais representam tratamentos iguais pelo teste de Tukey a 5\%.

Sobre o efeito alelopático do gênero Salvia, Viecelli e Cruz-Silva (2009) observaram que extratos de folhas frescas afetaram a germinação de sementes de alface, quando submetidas à concentração de $30 \%$ do extrato obtido por maceração, trituração e decocção. Neste trabalho foi observado apenas atraso na germinação. As sementes de leiteira sofreram influência do extrato bruto com folhas secas, enquanto que sementes de soja foram afetadas pelo extrato bruto das folhas frescas. $\mathrm{Na}$ literatura tem sido encontrados trabalhos relatando o efeito das plantas medicinais com potencial alelopático no controle de plantas daninhas como o trabalho de 
Cruz, Nozaki e Batista (2000), que demonstraram que o extrato bruto aquoso de capim-limão (Cymbopogon citratus (DC) Stapf.) e eucalipto (Eucalyptus citridora) na concentração de 30\% inibiu totalmente a germinação de sementes de Bidens pilosa L. Resultados semelhantes foram obtidos por Souza et al. (2002) e Cruz, Nozaki e Batista (2000), os quais verificaram que extratos aquosos na concentração de $10 \%$ das plantas medicinais capim-limão (Cymbopogon citratus (DC) Stapf.) e vetiver (Vetiveria zizanoides) inibiram significativamente a germinação de sementes de mentrasto (Ageratum conyzoides) e de picão-preto (Bidens pilosa L.).

Segundo Rodrigues, Rodrigues e Reis (1992), os compostos alelopáticos podem ser inibidores de germinação e crescimento, influenciando diretamente na emissão das radículas das plantas em teste, pois interferem na divisão celular, na permeabilidade das membranas e na ativação de enzimas. Pires et al. (2001) relatam que o aumento da concentração do extrato leva a uma drástica redução do índice mitótico, ocasionando paralisação do crescimento radicular em sementes de milho tratadas com extrato de leucena (Leucaena leucocephala Lam.).

Os resultados encontrados no experimento mostraram uma possível ação alelopática inibitória do extrato de sálvia sobre o crescimento do amendoim-bravo e uma ação estimulatória sobre o crescimento da soja. Alguns autores afirmam que as ações das substâncias aleloquímicas não são muito específicas, podendo uma mesma substância desempenhar várias funções, dependendo de sua concentração e composição química (RICHARDSON; WILLIAMSON, 1988) e da espécie alvo.

\section{CONCLUSÃO}

O extrato de sálvia, tanto de folhas frescas quanto secas, retardou o crescimento do amendoim-bravo e estimulou o crescimento da soja.

\section{REFERÊNCIAS}

CARVALHO, S.I.C. Caracterização dos efeitos alelopáticos de Brachiaria brizantha cv. Marandu no estabelecimento das plantas de Stylosanthes guianensis var. vulgaris $c v$. Bandeirante. 1993. 72f. Dissertação (Mestrado em Zootecnia) - Universidade Federal de Viçosa, Viçosa, 1993. 
CRUZ, M.E.S.; NOZAKI, M.H.; BATISTA, M.A. Plantas medicinais. Biotecnologia Ciência e Desenvolvimento, v. 15, p. 28-34, 2000.

GUSMAN, A.B.; MUCILLO, G.; PIRES, M.H. Efeito do citronelol sobre a germinação e desenvolvimento do amendoim bravo (Euphorbia beterophylla L.). Semina, v. 11, n. 1, p. 20-24, 1990.

KATO-NOGUCHI, H.; INO, T. Assessment of allelopathic potential of root exudate of rice seedlings. Biologia Plantarum, Praha, v. 44, n. 4, p. 635-638, 2001.

LORENZI, H.; MATOS, F.J.A. Plantas medicinais no Brasil nativas e exóticas. Nova Odessa: Plantarum, 2002.

MACIAS, F.A.; VARELA, R.M.; TORRES, A.; OLIVA, R.M.; MOLINILLO, J.M.G. Bioactive norsesquiterpenes from Helianthus annuus with potential allelopathic activity. Phytochemistry, v. 48, n. 4, p. 631-636, 1998.

MARTINS, E.R.; CASTRO, D.M.; CASTELLANI, D.C.; DIAS, J.E. Plantas medicinais. Viçosa: Ed. da UFV, 2002.

OLIVEROS-BASTIDAS, A.J. Él fenómeno alelopático. El concepto, las estrategias de estudio y su aplicación en la búsqueda de herbicidas naturales. Quimica Viva, v. 7, n. 1, p. 1-34, 2008.

PIRES, N.M.; PRATES, H.T.; PEREIRA, I.A.; OLIVEIRA, R.S.; FARIA, T.C.L. Atividade alelopática da leucena sobre espécies de plantas daninhas. Scientia Agrícola, v. 58, n. 1, p. 61-65, 2001.

RICHARDSON, D.R.; WILLIAMSON, G.B. Allelopathic effects of shrubs of the sand pinescrub on pines and grasses of the sandhills. Forest Science, v. 34, n. 1, p. 592596, 1988.

RIZVI, S.J.H.; TAHIR, M.; RIZVI, V.; KOHLI, R.K.; ANSARI, A. Allelopathic interactions in agroforestry systems. Critical Reviews in Plant Science, v. 18, n. 6, p. 773-796, 1999. 
RODRIGUES, L.R.A.; RODRIGUES, T.J.D.; REIS, R.A. Alelopatia em plantas forrageiras. Jaboticabal-SP: FCAV-UNESP, 1992. 160p.

SILVA, I.; FRANCO, S.L.; MOLINARI, S.L.; CONEGERO, C.I.; NETO, M.H.M.; CARDOSO, M.L.C.; SANT'ANA, D.M.G.; IWANKO, N.S. Noções sobre o organismo humano e utilização de plantas medicinais. 4. ed. Cascavel: Assoeste, 1995.

SOUZA FILHO, A.P.S.; GUILHON, G.M.S.P.; ZOGHBI, M.G.B.; CUNHA, R.L. Análise comparativa do potencial alelopático de extrato hidroalcoólico e do óleo essencial de folhas de cipó d'alho (Bignoniaceae). Planta Daninha, Viçosa, v. 27, n. 4, p. 647$653,2009$.

SOUZA, M.A.A.; BORGES, R.S.O.S.; STARK, M.L.M.; SOUZA, S.R. Efeito de extratos aquosos, metanólicos e etanólicos de plantas medicinais sobre a germinação de sementes de alface e sobre o desenvolvimento micelial de fungos fitopatogênicos de interesse agrícola. Revista Universidade Rural, v. 22, n. 2, p. 181-185, 2002.

VIECELLI, A.; CRUZ-SILVA, C.T.A.; Efeito da variação sazonal no potencial alelopático de Sálvia. Semina: Ciências Agrárias, Londrina, v. 30, n. 1, p. 39-46, jan./mar. 2009.

WANDSCHEER, A.C.D.; PASTORINI, L.H. Interferência alelopática de Raphanus raphanistrum L. sobre a germinação de Lactuca sativa L. e Solanum lycopersicon L. Ciência Rural, Santa Maria, v. 38, n. 4, p. 949-953, 2008.

Recebido em: 13 de dezembro de 2013 Aceito em: 20 de fevereiro de 2014 